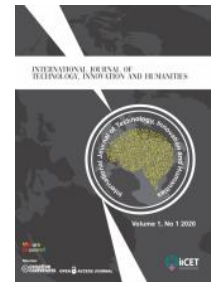

\title{
Innovation of air quality detector in passenger car using IoT
}

\author{
Farih Bin Deraman ${ }^{1}$, Asrudin Bin Mat Ali ${ }^{1}$, Normi Bin Muhamad ${ }^{1}$ \\ ${ }^{1}$ Department of Mechanical Engineering, Politeknik Sultan Mizan Zainal Abidin, Malaysia
}

\begin{tabular}{l}
\hline Article Info \\
\hline Article history: \\
Received Sep 26th, 2020 \\
Revised Oct 12th, 2020 \\
Accepted Nov 7th, 2020 \\
\hline
\end{tabular}

\section{Keyword:}

Air Quality

Detector

Passenger CarBlynk App

\begin{abstract}
The internet of things (IoT), is a system of interrelated computing devices, mechanical and digital machines, objects, animals or people that are provided with the ability to transfer data over a network without requiring human-tohuman or human-to-computer interaction (Gismalla \& Abdullah, 2017). The internet of things helps people live and work smarter as well as gain complete control over their lives. A passenger car is a road motor vehicle, intended for the carriage of passengers and designed to seat no more than nine persons. The problems occur in passenger car when there is no device that monitor the quality of air in the car's cabins. Air Quality Detector is an automatic system that being developed to send the value of Carbon Dioxide (CO2) level in car to LCD display and Blynk App. The existing low-end car do not have any system that can notify the passengers regarding the $\mathrm{CO} 2$ level in the car. As a solution, this innovation able to detect exact condition of carbon dioxide level in car to the LCD display and Blynk app to be warned by the passenger. Air Quality Detector has been simulated to run successfully in term of controlling and monitoring $\mathrm{CO} 2$ in the car.
\end{abstract}

(C) 2020 The Authors. Published by IICET.

This is an open access article under the CC BY-NC-SA license

(https://creativecommons.org/licenses/by-nc-sa/4.0

\section{Corresponding Author:}

Farih Bin Deraman,

Department of Electrical Engineering, Politeknik Ungku Omar, Perak, Malaysia

Email: farih@psmza.edu.my

\section{Introduction}

Nowadays, there are various kind of pollution faced by human including air and gasses pollution (Faber et al., 2012). One of the gas that can lead to sleepy and unconscious while in a car is carbon dioxide. When breathing, human exhale $\mathrm{CO} 2$, after that displace $\mathrm{O} 2$ in an indoor environment such as a vehicle cabin, leaving the environment $\mathrm{O} 2$ high. It is a major component in the car's exhaust fumes and if large quantities accumulate in the cabin it will be troublous. The problem with Carbon Dioxide is it is an odorless gas and hence humans will not even realize when they are breathing. Another reason for deaths while some one is sleeping in a car is a malfunctioning air conditioner. A weak AC will not be able to completely refresh the air inside the car and this will lead to increased carbon monoxide levels (Barnes et al., 2018). It reduces the blood's ability to carry oxygen to human cells and each of them die due to lack of oxygen.

An air detector is a device commonly fitted to any rooms, environment and situations. Its purpose is to automatically check the air condition whether it safe for human (Wu et al., 2019). The balanced gas 
compositions in the air will affected the air quality level (Rumantri et al., 2018). The use of carbon dioxide sensors inside cars is a good way of controlling the ventilation but it's also possible to detect people inside a parked vehicle. A traditional way of using a CO2 sensor is to know when to force air from the outside to the inside of the car. If the car is traveling in the forest the outside air quality is most likely better in terms of pollution compared to the air in on a busy street in the town. If the car monitors the outside air quality, it is possible to weigh the inside air quality to the outside air quality. If only one person is traveling in the car there is not as much $\mathrm{CO} 2$ exhaled into the interior.

Exhaled air is about 5\% CO2. If humans inhale all the air exactly once that would put the entire car's volume at $5 \% \mathrm{CO} 2$. The math can be done on car volumes and breathing rates and it's on the order of 3-10 hours to breathe the entire volume depending on the car and driver. 10\% CO2 is fatal but humans will pass out before that lack of oxygen.

It's worth noting that the human body cannot actually detect lack of oxygen. All breathing-related reflexes are triggered by $\mathrm{CO} 2$ concentration. Humans will immediately and notice any $\mathrm{CO} 2$ buildup capable of causing harm.

\section{Method}

A system of broad principles or rules from which specific methods or procedures may be derived to interpret or solve different problems within the scope of a particular discipline. Unlike an algorithm, a methodology is not a formula but a set of practices.

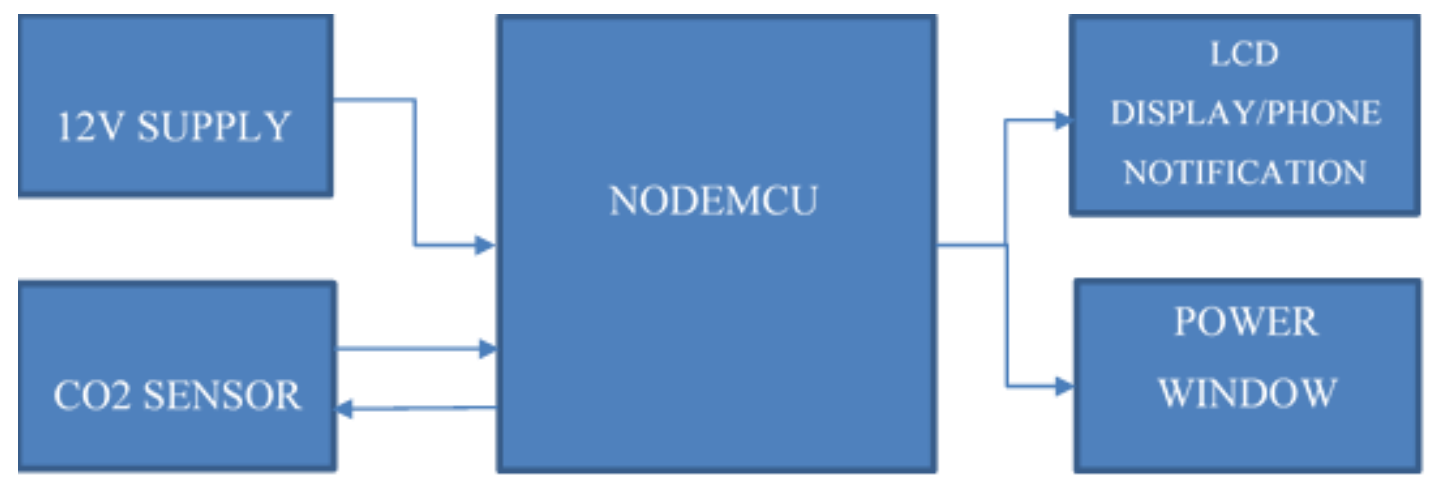

Figure 1 <Block Diagram of Air Quality Detector in Passenger Car Using IoT>

According to the block diagram above there are two inputs which are the 12V Supply and the Co2 sensor. The NodeMCU acts as the controller and the outputs are the LCD Display/Phone Notification and the power window. The $12 \mathrm{~V}$ is supplied by the car battery which also powers the Co2 sensor.

The sensor will begin detecting the Co2 levels as soon as it is connected to the battery. When it detects PPM levels more than 1000PPM, it will send a signal to the NodeMCU and the NodeMCU will give instructions to the power window to roll down and will also give instruction to the LCD to display "DANGER LEVEL". The sensor will get back a feedback from the controller. The sensor will send back a signal when the PPM value is less than 1000PPM.

Research design consists of flowchart for group and individual flowchart. Figure 2 shows the process begins when the $\mathrm{CO} 2$ sensor detects $\mathrm{CO} 2$ levels in car. Initially, when car user enters the car the PPM will naturally be less than 400PPM so the LCD will display "SAFE LEVEL". When the sensor detects values of more than 1000PPM the sensor will send a signal to the NodeMCU and the controller will send a notification to phone using BLYNK application and will display on the LCD "DANGER LEVEL". The controller will also actuate the power window to roll down automatically for 2 seconds. When the sensor detects values of less than 1000PPM it will actuate the power window to close automatically. the car user will also get a notification on phone and LCD displaying "SAFE LEVEL". The cycle continues again. 


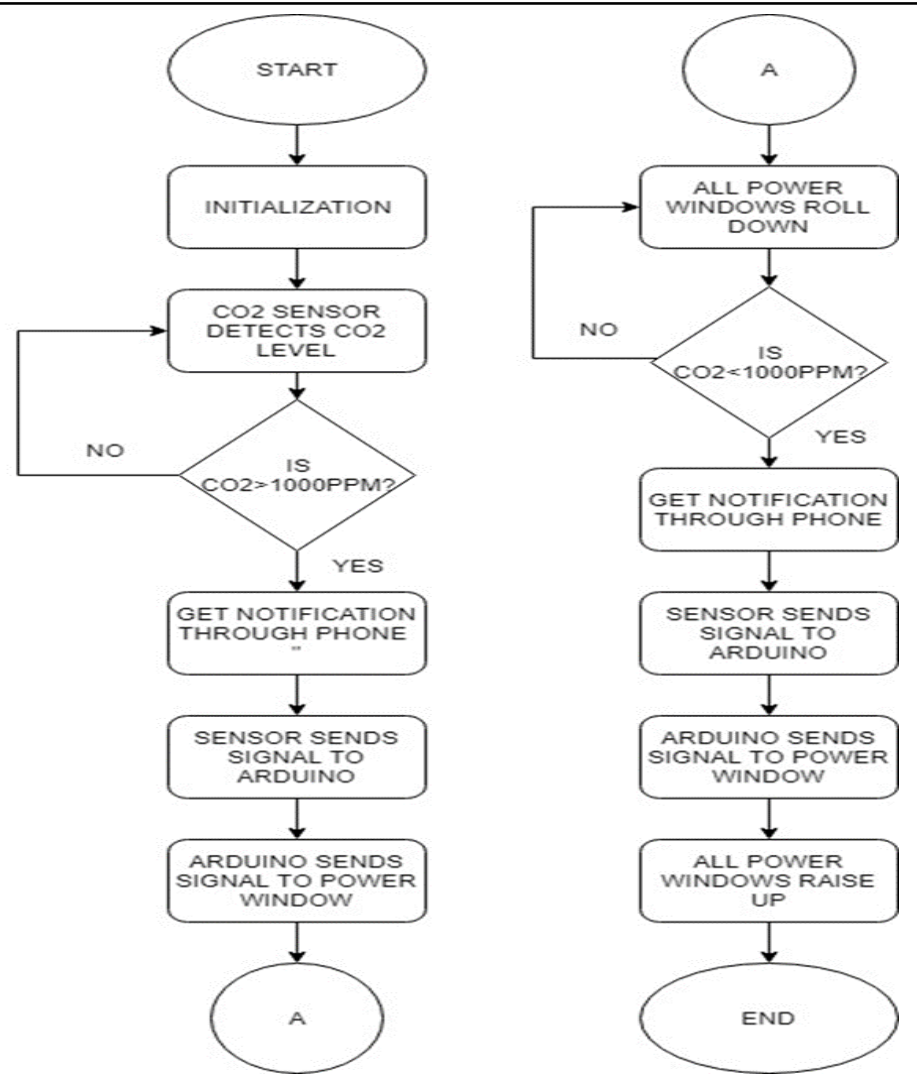

Figure 2. Air Quality Detector Flow Chart

\section{Results and Discussion}

Findings and data analysis are used to calculate the readings in Carbon Dioxide (CO2) level which is used in this project. It is important to calculate $\mathrm{CO} 2$ level to get the desired outcome which is performed to the power window. The power window is used as a mechanism to react with the $\mathrm{CO} 2$ level. For instance, when CO2 level is below 700 ppm (safe level) the power window will remain closed. But when the $\mathrm{CO} 2$ reaches $1000 \mathrm{ppm}$ (danger level) the power window will roll down for 2 second. When it detects danger level, it will send notification to phone, display "DANGER LEVEL" in LCD and will sound the buzzer. When the sensor detects safe level, it will raise the power window automatically signaling safe carbon dioxide level.

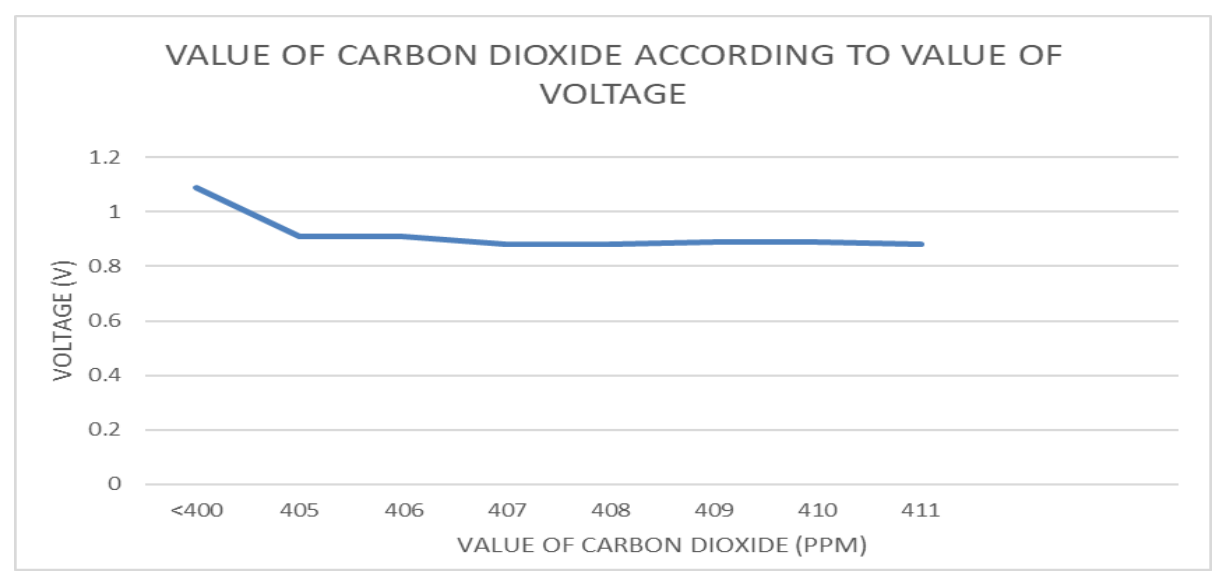

Figure 3 < Value of Carbon Dioxide According to Value of Voltage>

Figure 3 shows the value of $\mathrm{CO} 2$ in a controlled environment with steady air flow and volume of box of $13.94 \mathrm{~cm}^{2}$, the initial value of $\mathrm{CO} 2$ is obtained to be at $400 \mathrm{PPM}$ with $1.09 \mathrm{~V}$. After exhaling for 30 Seconds the 
following results are obtained. When the CO2 reaches $410 \mathrm{PPM}$ the voltage is at $0.89 \mathrm{~V}$. Using the information from this experiment the time needed for CO2 to increase to 1000PPM can be calculated as Table 1.

Table $1<$ Value of Carbon Dioxide $>$

\begin{tabular}{lc}
\hline Value of Carbon Dioxide (PPM) & TIME (SECONDS) \\
\hline 400 & 0 \\
410 & 30 \\
\hline
\end{tabular}

This value is for a box with volume of $13.94 \mathrm{~cm}^{3}$. As the result above table 1, when PPM value is 410 the time taken is 30 Seconds. It is found that for every 10PPM increase the time taken is 30 seconds. Therefore, the time taken for PPM to reach 1000 can be calculated.

Table $2<$ Calculated Value of Carbon Dioxide $>$

\begin{tabular}{lc}
\hline Value of Carbon Dioxide (PPM) & TIME (SECONDS) \\
\hline 10 & 30 \\
1000 & 1800 \\
\hline
\end{tabular}

From the table 2, it can be concluded that for sensor to raise until 1000PPM, it will take 1800 seconds (30 Minutes).

In the following analysis based on figure 4, the sensor is subjected to carbon dioxide up to 500 PPM. Then time was taken until the sensor detects 400 PPM. This analysis was done in a box with volume of $13.94 \mathrm{~cm}^{3}$. The time was started when the sensor detects 500 PPM and is stopped when it detects 400PPM. It can be observed that it takes up almost 14 minutes for the sensor to detect 400 PPM which is a safe level.

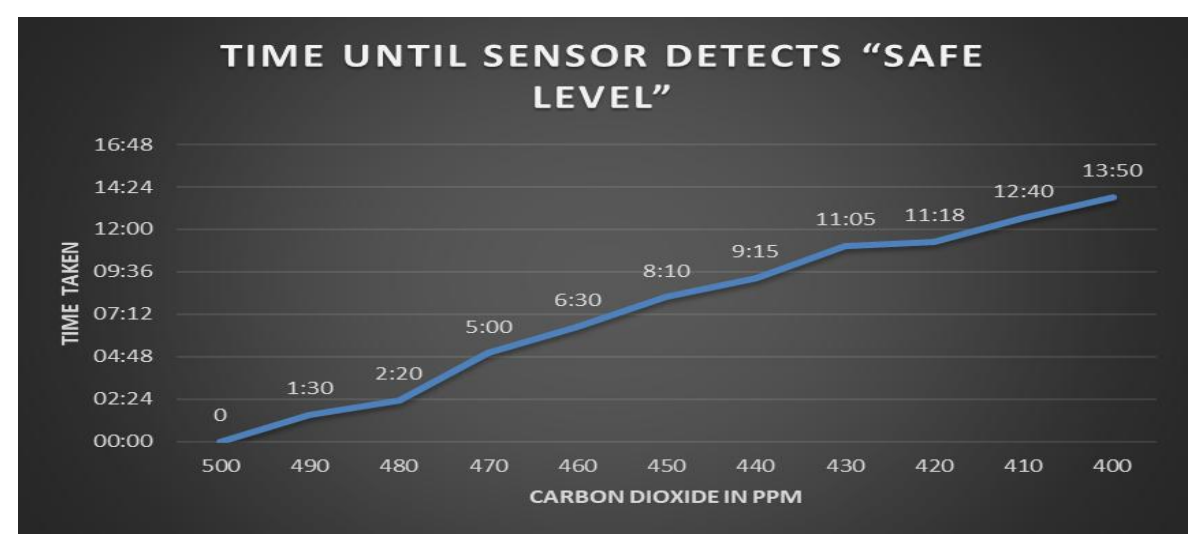

Figure 4 <Time Until Sensor Detects "SAFE LEVE">

This graph shows the time taken against the carbon dioxide level from 500PPM to 400PPM.

Table $3<$ Carbon Dioxide Level>

\begin{tabular}{|c|c|}
\hline LEVEL OF CO2 (PPPM) & EXPLANATION \\
\hline $250-350$ & Background (normal) outdoor air level. \\
\hline $350-1000$ & $\begin{array}{l}\text { Typical level found in occupied spaces with } \\
\text { good air exchange. }\end{array}$ \\
\hline $1000-2000$ & $\begin{array}{l}\text { Level associated with complaints of drowsiness } \\
\text { and poor air }\end{array}$ \\
\hline $2000-5000$ & $\begin{array}{l}\text { Level associated with headaches, sleepiness and } \\
\text { stuffy air }\end{array}$ \\
\hline$>5000$ & Toxicity or oxygen deprivation could occur \\
\hline$>40000$ & $\begin{array}{l}\text { Immediately harmful due to oxygen } \\
\text { deprivation }\end{array}$ \\
\hline
\end{tabular}


Table 3 shows the information from Occupation Safety \& Health (OHS) about the CO2 level. From the information, the value of CO2 is set for DANGER level to 1000PPM, NORMAL level to above 401PPM until 999 PPM and finally 400PPM and below for SAFE level. But since a prototype version is used, the levels set is a bit lower due to long time to reach 1000PPM.

\section{Conclusions}

From the analysis, it is found that the result this project is a successful as all the objectives are achieved. The first objective of this project is to design a product that can reduce $\mathrm{CO} 2$ in car. This is achieved as the sensor used detects $\mathrm{CO} 2$ levels in car

The second objective is to design a power window system that can be controlled automatically. This is also a success because when the sensor detects high $\mathrm{CO} 2$ levels in car it will actuate the power window to roll down automatically and when the $\mathrm{CO} 2$ in car is back to safe level it will close the window automatically again.

The third objective is to develop a system that gives notification to phone and displays message on the LCD Display. This objective is also a massive success as this project uses NodeMCU as the controller and can connect to WIFI. BLYNK is used as the interface to view the sensor values. When the CO2 value reaches dangerous levels BLYNK will give out a notification as a warning. The NodeMCU is also connected to LCD Display to emit messages such as "CO2: SAFE LEVEL", "CO2: WARNING LEVEL" and "CO2: DANGER LEVEL".

The final objective is to integrate a system using Arduino IDE. This is also achieved because the programming for this project uses Arduino IDE. Arduino IDE can also be used for different microcontroller such as Arduino UNO, Arduino MEGA, PIC controller and also many more with adjusting the programming. It was a good decision to use Arduino IDE to programme this project.

\section{Acknowledgments}

Authors gratefully acknowledge the support of Department Education of Polytechnic and Community College, Sultan Mizan Zainal Abidin Polytechnic and Mechanical Department Project Development Group to undertake this research activity.

\section{References}

Barnes, N. M., Ng, T., Ma, K. K., \& Lai, K. M. (2018). In-cabin air quality during driving and engine idling in air-conditioned private vehicles in Hong Kong. International Journal of Environmental Research and Public Health, 15(4). https://doi.org/10.3390/ijerph15040611

Faber, J., Brodzik, K., Łomankiewicz, D., Gołda-Kopek, A., Nowak, J., \& Świątek, A. (2012). Temperature influence on air quality inside cabin of conditioned car. Silniki Spalinowe, 51(1), 49-56.

Gismalla, M. S. M., \& Abdullah, M. F. L. (2017). Device to device communication for internet of things ecosystem: An overview. International Journal of Integrated Engineering, 9(4), 118-123.

Rumantri, R., Khakim, M. Y. N., \& Iskandar, I. (2018). Design and characterization of low-cost sensors for air quality monitoring system. Jurnal Pendidikan IPA Indonesia, 7(3), 347-354. https://doi.org/10.15294/jpii.v7i3.14444

Wu, Y., Liu, T., Ling, S. H., Szymanski, J., Zhang, W., \& Su, S. W. (2019). Air quality monitoring for vulnerable groups in residential environments using a multiple hazard gas detector. Sensors (Switzerland), 19(2). https://doi.org/10.3390/s19020362 